\title{
Unamuno
}

y

Croce

POr GAETANO FORESTA.

Con motivo de la celebracion del primer centenario del natalicio de B. Croce muchas voces se elevan por todo el mundo, para rendir un merecido tributo de gratitud y afecto al maestro de vida y de pensamiento. Me parece, por tanto, interesante recordar, a través de los documentos existentes (1), la relación que existió entre Unamunto ca crocer la cual pasa, de la congenialidad de ideas y sentimientos de amistad, a la esfera de los valores humanos a los que ambos se sintieron fuertemente ligados, dando como resultado una nueva afirmación de aquellos lazos espirituales que han caracterizado, en el curso de los siglos, la cultura española e italiana.

En la relación que existió entre Unamuno y Croce pueden distinguirse dos aspectos, bien definidos: el uno completamente humano, el otro científico; ambos armonizan y se integran ofreciéndonos la dimensión de aquel mundo, propio de los grandes hombres, que se impone como un ejemplo de la verdadera esencia de la cultura. En cuanto al aspecto humano, no dejaremos de subrayar los motivos que determinan el parentesco espiritual entre Unamuno y Croce: la pasión por el estudio; el carácter universal de su propia cultura, que los induce a recorrer el camino de la vida con una fidelidad que hace de ellos dos hom-

(1) Carlos Claveria: Temas de Unamuno. Ed. Gredos, Madrid. 1953. M. García Blanco: En torno a Unamuno. Historia de una Amistad. Ed. Taurus, Madrd, 1965.

Miguel de Unamuno: Obras completas. 
bres verdaderamente libres que no desperdician sus energías en una fácil adaptación al medio ambiente; la predisposición para recibir y acoger las vibraciones del pensamiento a efecto de dar a los demás el fruto de la constante presencia y el testimonio cotidiano de sus intereses hacia los acontecimientos no sólo literarios o artísticos, sino también, hacia aquellos de índole política y social, sin distinción alguna respecto al concepto fundamental que ellos tuvieron de la cultura, como participación integral del hombre en la vida de su propio país y del mundo; el decidido liberalismo político de ambos, como concepto ideológico y como profesión práctica en circunstancias adversas a su respectiva patria; el interés hacia el estudio de las letras y lenguas europeas. Hecho esencial, en fin, que documenta la relación frecuente y constante entre los dos, es la correspondencia epistolar que abarca de los años 1911 hasta 1921.

A través de las cartas pueden verse los intereses espirituales mutuos que vinculan a estos dos hombres: las múltiples manifestaciones de comprensión recíproca de las ideas expuestas en sus respectivos ensayos; las alusiones y los comentarios de Unamuno a algunas obras de Croce; el deseo de Unamuno de poder conocerlo personalmente, $\bar{y}$, en fin, ciertas afirmaciones que trascienden las zonas đe la amistad, puramente epistolar, y que constituyen una prueba de afecto hacia Italia y su civilización.

\section{Biblioteca de Letras}

La correspondencia, asorg como ha comelli fido ordenada por Manuel García Blanco, comprende 11 cartas: la primera de ellas lleva la fecha del 23 de mayo de 1911 y la última (una postal) la del 26 de octubre de 1921. EJ exilio de Unamuno, durante el gobierno del general Primo de Rivera, interrumpe la correspondencia, por lo que los ecos de la amistad, documentada por la correspondencia, se apagan. Unamuno vuelve a su patria en 1930. Después de esta fecha, se quedan, acá y allá, en los escritos de Unamuno, recuerdos y testimonios que, aunque no sean reveladores de aquella adaptación del pensamiento y sentimiento unamuniano a las doctrinas de Croce, manifestada expresamente en otros escritos, atestiguan, sin embargo, el interés de Unamuno hacia la obra y la acción que Benedetto Croce continúa desarro. llando en Italia.

Entre las cartas merece una atención particular aquella del 23 de mayo de 1911, con la cual Unamuno envía el prólogo, que, apenas, había terminado de escribir, a la traducción española de la "Estética", hecha por el salmantino, José Sánchez Rojas. ex-alumno de la Universidad de Bolonia. 
-Ilustre Profesor: Por este mismo correo le remito el pró logo que acabo de escribir para la traducción que de su "Estética" ha hecho Sánchez Rojas. Mi prólogo no está hecho sobre la traducción española, que no conozco, sino sobre el original italiano. Y es uno de los mayores favores que a Sánchez Rojas debo el que, al pedirme ese prólogo, me haya hecho leer su excelente obra. De usted tenía noticia y había leído cien veces su nombre y comentarios a su labor, pero, fuera de alguno que otro artículo de revista, no conocía obra suya. Y he quedado aficionadísimo. Le debo no pocas enseñanzas y más sugestiones. Gracias por ello. Me ha dado a conocer algunos escritores, como De Sanctis, del que, apenas, tenía noticia. Ya sé, ahora, a dónde he de acudir cuando quiera orientarme en la literatura clásica italiana, que en parte, y sólo en parte, conozco.

Sucesivamente, Unamuno, fiel a su temperamento, no deja expresar su desaprobación, al comentar la frase que se le escapa a Croce, en el capítulo XII de su "Estética", dedicado a los estetas alemanes menores: "De estos, se lee en la traducción castellana, casi ninguno tuvo resonancia afuera de Alemania; simplemente Krause fue importado en la siempre desventurada España"; y, cual si le hublesen herido en su orgullo español, Don Miguel escribe:

- "Me dolió al leerlatio aun cuando no esté mal en la aplicación inmediata a quêse refiere Nos duele siempre la compasión de los extraños, y más de los que, como Croce, parecen, en parte al menos, conocernos. Siempre desventurada España... ¿Por qué? ¿Cuál es su desventura? No podemos juzgar de la exactitud y el valor del epíteto hasta no saber toda la extensión del sentido que su autor le da y en el que lo funda. No sé si en Italia, y aun por críticos de la perspicacia y la independencia de criterio artístico de un B. Croce, se nos conoce lo bastante para juzgar de nuestra ventura y desventura...

Croce, dándose cuenta de la desaprobación de Unamuno, con la hidalguía que le era propia, contesta, con fecha del 5 de junio, agradeciendo, cordialmente, y pidiendo disculpas de su "boutade" que se le había escapado durante la primera impresión de su libro y que, después, había olvidado quitar.

-Cuando escribi: "La siempre desventurada España", a propósito del Krausismo español, lo hice en broma; pensaba en las corrientes del peor positivismo europeo que, entonces, la recorrían, así como en la presencia del peor sistematismo ale- 
mán que había sufrido unos diez años antes. Y aquella frase estaba dirigida, más bien contra la pedantería filosófica y la ramplonería positivista que contra España, su literatura y su arte, cuyo pueblo y cuya historia siempre han tenido para $\mathrm{mf}$ una gran fascinación.

En la nueva edición italiana, que ahora se prepara de la "Estética", quitaré aquella frase; mas, no es posible hacerla desaparecer de la traducción española, porque Ud. tendría que suprimir muchas páginas de su bella introducción. Prefiero, pues, que quede a los ojos de todos mi pecado, a fin de que no falten aquellas páginas del castigo. Le agradecería, añadir, solamente, una nota llamando la atención, en nombre del autor, que se trata de una frase en broma, escrita por "incidens", sin darle demasiada importancia y que Croce, antes de ser escritor de filosofía y estética, era un hispanófilo muy conocido y había publicado muchos ensayos de cultura española. Esta es la verdad.-

En efecto, en las ediciones posteriores, Croce sustituyó la frase, que había suscitado el resentimiento de Unamuno, con la siguiente: "Apenas el Krause fue introducido en España". Unamuno daba acto de la solueión adoptada por Croce, escribiendo, con fecha del 9 de junio de 1911:

\section{Biblioteca de Letras}

-Me ha parecido losmiejorellifradirona mi prólogo una traducción parcial de su carta que no es puramente personal; y luego añado por mi cuenta: $\mathrm{Y}$ ahora soy yo quien digo que no debe desaparecer de la traducción dicha frase, y no por los desahogos de suspicacia que en este mi prólogo ha provocado, sino por haber dado lugar a esta nobilísima carta en que resplandece todo el sereno espiritu del ilustre filósofo napolitano. Y después de sus explicaciones soy yo quien hago mía su frase. Porque pasó, al parecer, el peso de aquella peor sistematización de filosofía tedesca; parece que va pasandó la ramplonería positivista, refugiada aun en bibliotecas baratas de avulgaramiento más que de vulgarización pseudocientífica; pero, lo que no parece que quiere pasar de nuestra desventurada patria es la pedantería filosófica tedesca; parece que ahora toma una nueva y más sutil forma de vacuo intelectualismo y amenaza infectar nuestro arte, que en los buenos tiempos supo defenderse de tales infecciones; y como creo que esta "Estética", escrita por un italiano hispanófilo, que bajo el clarísimo cielo de Nápoles, todo luz, rodeado de las memorias de Vico, de Bruno, de Campanella y De Sanctis, de otros grandes, claros y luminosos espíritus, ha 
logrado disipar hórridas nieblas septentrionales, sacando de ellas, al disiparlas, el rocío vivificante que era su tuétano; como creo, digo, que esta "Estética" puede contribuir en algo a defendernos de esta nueva pedantería que nos amenaza, por eso creo obra altamente patriótica darla traducida a nuestra hoy todavía en no poco desventurada España.-

La polémica que aflora en el contenido de las cartas citadas, además de ser un espléndido ejemplo respecto a la forma de acercarse a la razón y a la verdad de los hechos, nos ofrece la ocasión de examinar las consonancias y afinidades del pensamiento de Unamuno con el de Croce sobre el problema estético.

La lectura meditada y apasionada de la Estética Crociana despertó en Unamuno múltiples reacciones, como demuestra la siguiente confesión:

-Por mi parte, debo a B. Croce no pocas enseñanzas, corroboración de puntos de vista, esclarecimiento de ideas que bullían en mí aún confúsas; expresión neta de oscuras impresiones que en mí germinaban; solución de dudas; unión de cabos sueltos y de incoherentes fragmentos del pensamiento; pero le debo también el que me haya hecho formular nuevas preguntas...

\section{Biblioteca de Letras}

No olvidemos, al rerge Puccinelli Converso" respecto, la rebelión de Unamuno al concepto de la religión que tuvo Croce; su aceptación, como filósofo, de la teoría linguística del filósofo italiano, a pesar de su reserva desde el punto de vista naturalístico o sentimental.

Unamuno, como escribe Carlo Claveria, (2) poco amigo de dogmas o preceptos, se sintió atraído por el libro de Croce: "Confieso contarme en el número de aquellos a quienes les atraen muy poco o nada los tratados de estética, y más si son de filósofos".

Pero esta "Estética" es distinta, porque, "no a pesar de ser una obra de robusta y segura filosofía, sino precisamente por serlo, es una obra fuertemente liberadora y sugestiva para un artista; una obra revolucionaria"

Reconoce Don Miguel que no todos los estetas se proponen

(2) Carlos Claveria: Temas de Unamuno. Biblioteca Romántica-Hispánica, Ed. Madrid, 1953, págs. 125 y siguientes. 
preceptuar reglas a que los artistas hayan de sujetarse y que no entra Croce entre esos. Unamuno debió encontrar, en las páginas de la "Estética", motivos para reafirmarse en la importancia de una crítica artística que interpreta y recrea ("pues criticar es renovar", observa en su prólogo). Lo mismo sucedió en su obra cervantina "Vida de Don Quijote y Sancho". Con la "genialidad crítica", propugnada por Croce, debía simpatizar Unamuno siempre dispuesto a meterse en las obras de los demás, y a hacerlas suyas. Pero, tal vez, no es este el punto más importante en que descubre reflejadas sus propias convicciones.

$\mathrm{Si}$, en el prólogo de la traducción española, recomienda repetidamente su lectura a los escritores, es porque Unamuno cree que ha de darles mayor conciencia de su obra y de su capacidad creadora: "Leyéndola adquirirán los artistas mayor y me. jor conciencia de su independencia artística", así escribe.

Esta conciencia de independencia, ese sentimiento de liberación, esta nueva aptitud de examinar y examinarse por dentro, (recordamos que para Croce la expresión es, ante todo, expresión interior antes de ser comúnicada), encontrarán su reflejo en lo que pudiera llamarse "Eștética Unamuniana", en sus teorías tardías y a posteriori acerca de sus creaciones literarias. La teoría de la nivola es posterior a las nivolas o novelas mismas (3) y cuando Gerapdo Dieg de pide una "poética" para una

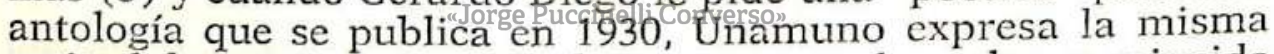
actitud de antaño, negatoria de preceptos y de reglas, y coincide con la tendencia crociana de no dar una preceptiva, de no definir en particular obras de arte ni expresiones artísticas concretas y de atenerse técnicamente a los resultados de la creación literaria: "Un poeta es el que se desnuda con el lenguaje rítmico de su alma... El mundo espiritual de la poesía es el mundo de la pura heterodoxia $\mathrm{o}_{6}$ mejor, de la pura herejía. Todo verdadero poeta es un hereje, $\mathrm{y}$ el hereje es el que se atiene a postceptos y no a preceptos, a resultados y no a premisas, a creaciones, o sea poemas, y no a decretos, o sea dogmas. Porque el poeta es cosa de postcepto y el dogma es cosa de precepto". (4)

Otra coincidencia de las ideas de Unamuno con la doctrina estética de Croce es aquella relativa a los géneros literarios. Cro-

(3) Véase un resumen en L. Livingstone: Unamuno and the aesthetic of the novel. En "Hispania", XXIV-1941, páginas 442 y siguientes.

(4) Gerardo Diego: Poesía Española. Antologia 1915-1931. Madrid, 1932. págs. 18 y sigs. 
ce destruye, según Unamuno, "la supertición de los géneros". Al escribirle a José A. Balseìro, para hacerle notar la "disección" a que sometía la obra unamuniana, en su libro "El Vigia", Unamuno afirma:

-Y voy a eso del ensayista por un lado, el novelista de otro y de otro el poeta. Usted conoce, sin duda, la "Estética" de Croce, cuya traducción española prologué. Lo mejor de ella -derivado de De Sanctis- es combatir esos pseudoconceptos de los géneros literarios... A mí, que soy un lector directo, la intención del autor me importa poco. Si lo que de él gusto me gusta, me tiene sin cuidado que me diese gato por liebre. Soy de los pocos lectores que no me intereso en si se solucionan o no los problemas de una novela, nivola, ensayo, poema, etc., si los tiene. Me preocupa más lo que llamaria metablema o trayecto. El camino y no la meta... y es que no hay sino el camino... No me envanezco de haber creado un género con eso de la "nivola"; sino que inventé la palabreja para destruir - si Io conse guía-, burlándome de eso de los géneros... (5)

En cuanto al aprecio que Unamruno hace de la "Estética" de Croce, basta con citar algunas expresiones del mismo prólogo, adonde, por ejemplo, define la "Estética": "una obra de ciencia" y, al mismo tiempo, de arte; una estética filosófica hecha por un verdadero artistage complilieden ser los diálogos de Platón; obra de arte por la ejecución, por la sobriedad potentemente expresiva, por su prosa limpia y animada; por el calor interior persuasivo que atrae al lector";.

El 16 de octubre de 1912, Unamuno, refiriéndose a una carta que le había escrito, anteriormente, B. Croce, le pide el envío de la "Logica come scienza del concetto puro" y de la "Filosofia della pratica"; al mismo tiempo le anuncia la publicación de su obra "Vida de Don Quijote" y le expresa su ardoroso deseo de volver a Italia. Termina su carta, deseando, con motivo de la histórica victoria italiana sobre los Turcos, prosperidades para nuestra patria.

- Al recordar su pasada oferta, me propongo no sólo recrear mi intelecto y aprender, en esas obras, sino aprovecharlas para un estudio sobre las corrientes actuales de la filosofía. Le

(5) Los textos completos en : J. A. Balseiro. B. Ibañez, Unamuno, Valle Inclán, Baroja Cuatro individualistas de España. "Chapell Hill, 1949, pág. $104 \mathrm{y}$ sigs. Véanse las observaciones sobre "los géneros literarios de Unamuno" de J. Marías en "La filosofía española actual". Buenos Aires, 1948, pág. 46 y siguientes. 
debo a Ud. el conocimiento de la "Storia della Letteratura italiana" de De Sanctis, que leí con fruición, la primavera pasada, y el de la "Storia della filosofia contemporanea" de Windelband:

Por mi parte, preparo la publicación de los ensayos sobre el "Sentimiento trágico de la vida", que en la revista "España moderna" he venido publicando, y se están corrigiendo, en Florencia, las pruebas de la traducción italiana de mi "Vida de Don Quijote".

Ardo en deseos, como ya creo haberle dicho, de volver a esa Italia, que a mis veinticinco años recorrí, y volver a ver al cabo de veintitrés esa Nápoles cuya visión clara y radiante yace en el fondo de mi ser. Deseando prosperidades a Ud. y a esa generosa Italia, que ha provocado el principio del fin de la barbarie turca (que Lepanto se corone de una vez), queda suyo affmo... admirador y amigo.

No existe la respuesta de Cloce a la carta anterior de Unamuno; en su biblioteca, empero, se encuentran los ejemplares de las obras que había solicitado, eon las anotaciones que Unamuno había hecho. Se encuentra, en cambio, la carta de Unamuno, escrita con fecha 13 de noviembre de 1912, en la que comunica a Croce haber recibidgl las edras mencionadas.

-Recibí, señor mío y amigo, su "Logica" y su "Filosofia della pratica" y estoy leyendo la primera. He recibido, después, su memoria sobre la historia.

Gracias por una y otra, que me sirven no sólo de enseñanza, sino de solaz y de consuelo y ánimo en medio de luchas de carácter práctico para levantar la conciencia moral y política de esta patria.

Ecos de la lectura de estas dos obras de B. Croce se notan en los ensayos de Unamuno que fueron publicados, después, en la obra "Sentimiento trágico de la vida" y que así rezan:

"Con muy hondo sentido B. Croce, en su filosofía del espíritu, junto a la Estética como ciencia de la expresión y la lógica como ciencia del concepto puro, dividió la filosofía de la práctica en dos ramas: economía y ética. Reconoce, en efecto, la existencia de un grado práctico del espíritu, meramente económico, dirigido a lo singular, sin preocupación de lo universal. 
Yago o Napoleón son tipos de perfección, de genialidad económica, y este grado queda fuera de la moralidad. Y por él pasa todo hombre, porque, ante todo, debe querer ser el mismo; como individuo, y sin ese grado no se explicaría la moralidad, como, sin la estética, la lógica carece de sentido. Y el descubri-miento del valor normativo del grado económico, que busca lo hedónico, tenía que partir de un italiano, de un discípulo de Maquiavelo, que tan hondamente especuló sobre la "virtud; la eficacia práctica, que no es precisamente la virtud moral".

"Hay en la Lógica de B. Croce unas páginas intensísimas, y en el fondo trágicas, en las que establece que el error procede de la voluntad y que es algo de origen ético. El que se equivoca es, en el fondo, porque quiere equivocarse. Páginas que abren muy amplios y muy profundos horizontes al que las lee y medita, salvando su aparente paradoja".

La noticia de la publicación de dos artículos de Unamuno, en la prensa de Buenos Aires, relativos a la obra de Croce: "La Spagna nella vita italiana durante la Rinascenza" tardó mucho en llegar al conocimiento de Croce; (no olvidemos que Europa ya está en guerra) y debiố ser el mismo Don Miguel el que se la diera, en una carta que no se ha conservado; así se desprende de esta postal que sulamigo le envía desde el Norte de Italia. "Jorge Puccinelli Converso"

-Desde hacía dos meses estoy lejos de Nápoles e ignoro si allá hayan llegado los volúmenes cuyo envío Ud. me anuncia. Si ya han llegado, los encontraré en mi casa, el próximo mes de octubre y, entonces, le daré noticia y le reiteraré mis agradecimientos que, desde ahora, le anticipo.

Me gustaría mucho leer lo que ha escrito en "La Nación" sobre las relaciones entre España e Italia en la época del Renacimiento. ¿Podría enviarme una copia de aquel diario?

Mi dirección está puesta arriba y se la indico al margen.

Confiamos en una temporada más tranquila para una mejor actividad intelectual y para el necesario intercambio de ideas entre los pueblos. Ahora estamos "mutilados"

Saludos cordiales de su affmo. B. Croce.

Viu' (Torino) 12 - VIII - 1917. 
La publicación del libro de Croce: "La Spagna nella vita italiana durante la Rinascenza" ofrece a Unamuno la oportunidad de expresar su estimación y admiración hacia el filósofo italiano, en dos artículos que llevan la fecha del mes de noviembre de 1916 y que, publicados en "La Nación" de Buenos Aires, respectivamente, el 24 de diciemhbre de 1916 y el $1^{\text {o }}$ de enero de 1917, se encuentran reunidos, ahora, en el tomo $\mathrm{V}^{*}$ de las obras completas, bajo los títulos: "Italianos y Españoles en el Renacimiento" (Obr. Compl. Vol. V', pgs. 146-153) y "La decadencia hispano-italiana" (Obr. Compl. Vol. V’, pgs. 154-162).

Unamuno, después de haber definido el carácter del histcıicismo crociano y su inspiración íntima a las fuentes italianas de Vico y De Sanctis y, además, a aquellas alemanas de Hegel, afirma que el filósofo italiano representa, en cierto modo, el historicismo en contra del naturalismo de la segunda mitad del pasado siglo XIX, en contra de lo que se llamó positivismo, y fue una especie de escolástica que obraba con pseudoconceptos y que, en rigor, reducía las explicaciones a clasificaciones. Exalta a Croce como un hispanófilo ł uno de los más destacados entre los que conocen la histofia y-la literatura española.

"Si por hispanófilo se entiende esto: uno que estudia y conoce con el amor que todotectudio y todo conocimiento llevan consigo, el espíritu españolictallicomosen la historia, las letras y las artes se revela, Croce es, con Eugenio Mele, con Arturo Farinelli, con Papini, con Savy López, con tantos otros italianos de hoy, de los mejores y mayores hispanófilos que haya.

En cuanto a la manera como Croce trata la historia, Unamuno escribe: ¿Croce no es un abogado? quiero decir que no es un espíritu que vaya, a tiro hecho, a buscar argumentos para sostener y defender una tesis previa, un prejuicio, adoptado por el interés y la pasión. No se acerca a la historia como se acerca a ella un político, como a un arsenal de armas con que pelear por su partido.

Aspira, siempre, a comprender y a comprenderlo todo y a explicarlo con aquella explicación que lleva, ya, en sí, un valor moral.

Al presentar la obra citada, Unamuno se preocupa de prevenir las acusaciones que puedan promover los "hispanófilos" cuando lean el capítulo VI? que trata de la reacción de la cultura italiana en contra de la "barbárica" invasión española. No- 
bleza de sentimientos y dignidad lo llevan, por encima de las polémicas de ciertos patrioteros celosos e incomprensivos, para afirmar serenamente, que: "es preciso reconocer que casi toda invasión de un pueblo en otro es bárbara y lo es más, cuando el pueblo es menos culto, menos civil, menos cometido que el pueblo invadido".

La visión del glorioso Renacimiento italiano induce a Unamuno a considerar la superioridad de los insignes artistas, literatos, poetas, hombres de ciencia, navegantes y políticos italianos, quienes dieron a aquella época un sello de inmortal grandeza, por lo que no le impresiona el hecho de que "los italianos de la época del Renacimiento, políticamente oprimidos y vejados, sin verdadera independencia, se reconocieran, y con razón, superiores en la cultura y en la civilización".

Después de una erudita disquisición sobre el adjetivo "bárbaro" usado en su sentido helénico y etimológico, Unamuno analiza, siguiendo el pensamiento de Croce, la acusación de barbarie hecha a la dominación española en Italia.

Croce asocia los dos pueblos nó sólo en la gloria del Renacimiento, sino, también, en la yuina de la decandencia; Unamuno, aceptando la tesis crociăna, en su segundo artículo: "La

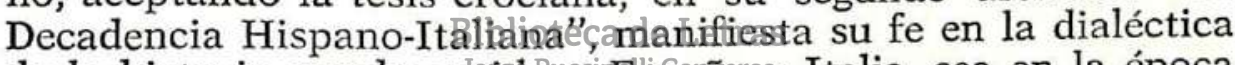
de la historia que ha unfłdouga Españase Italia, sea en la época áurea del Humanismo y del Renacimiento, sea en la época de la decadencia.

Al tratar Croce de la decadencia hispano-italiana sostiene que no fue España la causante de la decadencia italiana, sino que ambas decayeron por análogas causas. Desde mediados del siglo XVI hasta comienzos del XIX faltó en Italia toda vida política y sentimiento nacional; la libertad de pensamiento se agotó; empobrecióse la cultura; la literatura se hizo amanerada y vulgar; las artes figurativas y arquitectónicas se abarrocaron y de esto se ha querido culpar a España (Obras completas. Vol. V, pág. 158).

Mas, como Croce, Unamuno reccnoce que: la verdad acerca de la vida de aquellos siglos hay que buscarla por otra parte, o sea reconocer que Italia y España eran ambos, en aquel tiempo países en decadencia. (6).

(6) B. Groce: La Spagna nella vita italiana durante la Rinascenza. Bari laterza cap. XII página 263, 1921. 
Es preciso corregir el error, afirma Croce, de figurarse como una eficacia maléfica ejercida por España sobre Italia lo que fue analogía o comunidad de proceso histórico, a lo largo del cual es cierto que España dio, pero también recibió e Italia dio y recibió, a su vez. (7)

Unamuno cita, extensamente, las páginas de Croce sobre la influencia española en Italia, desde el siglo XVI hasta el siglo XVIII, y sobre las figuras de nuestro Renacimiento en el mundo de la cultura y del arte, para concluir en un acertado elogio del libro de Croce. A propósito del envío del "Contributo alla critica di me stesso" Unamuno no deja de expresar su gratitud y su aprecio, escribiendo, con fecha 13 de agosto de 1918:

-He recibido sus cartas: EI "Contributo alla critica di me stesso" me interesa muchísimo. (Es el hombre, el espíritu, lo que encadena $\mathrm{mi}$ atención y $\mathrm{mi}$ afecto intelectual) el "amor intellectualis" spinoziano. A la vez me he quitado el mal sabor de mente que me dejaron ciertas elucubraciones materialistas de Mr. Gustave Le Bon sobre la evolución de la materia.

La carta continúa dando noticias de su segundo viaje a Italia con motivo de su visita al frente de guerra. Unamuno manifiesta, además, su pena por no haber podido saludar al maestro, en Roma; se detiene en evocar,ccon nostalgia, los espléndidos paisajes de nuestros Alpes y renueva su deseo de volver a ver Italia, en un clima de paz, cuando acabe la guerra.

-Hace cosa de un año, en el pasado septiembre, volví a esa Italia. Fui a visitar el frente, estuve en Milán, Udine, Goricia, el Cador, Venecia, etc. No'pude, bajar a Roma, como fue mi deseo, ni buscarle. Tomé aire y sol, vi paisajes espléndidos, como el de Cortina D'Ampezzo, pero no tuve ocasión de entretenerme con mis buenos amigos de ésa. Cuando acabe esta guerra y con ello se reanude la del espíritu, en paz material relativa - procuraré volver a esa tierra.

Otro testimonio, no menos importante, de su constante interés hacia la actividad y la obra de Croce, es el artículo que Unamuno escribió para el diario "El Sol" de Madrid, el 25 de marzo de 1932, bajo el título: "EI'liberalismo español". El artículo, nace de la lectura del libro de Croce: "Storia d'Europa nel secolo decimonono".

(7) Idem: cap. XII, pág. 264. 
- "Este comentario, escribe Unamuno, lo es a unas palabras de B. Croce, nuestro amigo, amigo de España, pues que la conoce bien. (Basta, entre otras cosas leer: "La Spagna nella vita italiana durante la Rinascenza") en su reciente obra, de este año, "Storia d'Europa nel secolo decimonono". La ha precedido en "Storia d'Italia dal 1871 al 1915", en que el más grande pensador de Historia con que hoy cuenta Italia, y no inferior a cualquier otro del mundo civilizado actual, afirmaba en esa perturbada Italia del fascismo, donde se trata de ahogar toda libre espontaneidad del espíritu, y ello a nombre de la nación".

Unamuno se basa en el primero de sus capítulos, el que lleva por título "La religión de la libertad" que para él es el liberalismo, cuyo aspecto religioso reside "no ya en una mera concepción, sino en un sentimiento y una intuición de la realidad de la vida universal de la historia".

Como escribe M. García Blanco, el núcleo y entraña de su comentario es un pasaje dell segundo capítulo: "Las fés religiosas opuestas". - No carece de ironía el hecho de que la nueva postura espiritual recibiese-st bautismo donde menos se habría esperado; del país-que más que cualquier otro europeo se había quedado cerrado a la filosofía y a la cultura modernas, del país por eminencia medieval y escolástico, clerical y absolutístico, de Espanta, ofqua dacuhter, entonces, el adjetivo liberal con su contrapunto to de servir.s' Es esta ironia del hecho histórico y del hecho linguiístico - que son uno mismo- la que estamos comentando.

Pocos meses después, el 19 de mayo de 1932, Unamuno analiza en otro artículo: "Don Marcelino y la Esfinge", aparecido, también, en el diario "El Sol", un juicio de Croce sobre Menéndez y Pelayo, que puede leerse en las obras completas. Tomo Vo, págs. 402-405.

La afirmación crociana relativa a la creación de los términos "liberal" y "liberalismo" permanecerá en su recuerdo, durante aquellos años, y ese recuerdo se despertará aún más con la lectura del libro de otro escritor italiano, Nicola Cuneo, intitulado: "España católica y revolucionaria", publicado en Milán, en 1934.

Unamuno dedicó a la lectura del libro de Cuneo dos artículos. El primero "España católica y revolucionaria", reproduce el título del libro; el segundo tiene como título la famosa 
expresión del Carducci: "La afanosa grandiosidad española". Los dos artículos, publicados en el diario madrileño "Ahora". respectivamente, con fecha del 27 de junio y 13 de julio de 1934, evocan, aunque de manera distinta, los motivos que Unamuno había expresado a propósito del libro de Croce.

En 1923, Unamuno, considerando la crisis de justicia y de libertad en la vida poética nacional de aquel entonces, amargamente comenta: "Está en decadencia el sentido de justicia, con eso de la eficacia. Es el triunfo de Maquiavelo o, como diría Croce, el triunfo de la economía en el sentido crociano sobre la ética. Salus populi lex esto.

Finalmente, he aqui, otro pasaje que se remonta a 1934 , relativo a la personalidad de Croce, como filósofo: "La obra de Feuerbach como la de Strauss, fue contemplativa, filosófica, pero de contemplación histórica. Y últimamente, la de B. Croce, el último gran hegeliano ha terminado sus especulaciones filosóficas en contemplaciones históricas. Que es la historia donde hay que buscar el universal concepto...".

A través de la lectura de las cartas y de los ecos que la misma correspondencia proyecta en las obras de Unamuno y en las de Croce podemos afirmar con las palabras de $\mathbf{M}$. García Blanco, que "ambos lograron un mutuo y acertado conocimiento de sí mismos.

Unamuno, al menos, supo ver en Groce la dimensión humana de su figura y así se lo descubre cuandó recibe el "Con" tributo alla critica di me stesso", cuya lectura le sugiere el juicio que ya hemos referido y que repetimos: Me interesa muchisimo. Es el hombre, el espíritu, lo que encadena mi atención y $\mathrm{mi}$ afecto intelectual, el amor intelectualis spinoziano. $\mathrm{Y}$ Croce debio buscar a Unamuno, preferentemente, en sus vibrantes y dramáticos Ensayos. Que Croce fuese esencialmente, historiador $\mathrm{y}$ filósofo y Unamuno poeta y literato, lejos de dificultar el diálogo lo hacía más íntimo y cordial". 